\title{
THE IMPORTANCE OF ILLUSTRATIONS IN TREATING SHORT-TERM MEMORY IN CHILDREN WITH SPECIAL ABILITIES
}

\author{
Rania Ismat Muhammad Al-Sayed AL-QARIA *
}

Department of Printed Designs, Faculty of Fine Arts, Alexandria University, Egypt

\begin{abstract}
Memory plays an essential role in the educational process and developing the abilities and skills of children in general and children with special abilities in particular, as it is the store responsible for preserving information and experiences responsible for developing their social, communication and cognitive skills. The division of memory into short-term and long-term memory goes back to the nineteenth century, where it was assumed that memories move from the store of short-term memories to the store of long-term memories after a short period, with different mechanisms of this transfer and about whether all memories or only some of them. Short-term memory is also called primary or active memory, and it means the ability to keep a small amount of information in the mind in an active and accessible state for a short period of time, that is, the short-term storage of information without including processing or organizing the material stored in the memory. A large percentage of children with special abilities appear to have a problem of limited short-term memory, which is known as "spontaneous decay" and in order to overcome this and retain information for a longer period, the information must be repeated or reviewed periodically, either by uttering it or repeating it in the mind, or by finding more attractive ways to focus the information. And the research deals with the role of the illustrations in the treatment of short-term memory responsible for the completion of the learning process.

Keywords

Illustrations, Treating, Short-Term Memory, Children, Special Abilities.
\end{abstract}

\section{Introduction}

Memory is extremely important in the lives of individuals in general, and for children in particular, and specifically children with special creative abilities, as memory integrity is linked to the functions of the mind while preserving the quality of impressions, and the importance of memory appears in its use in the affairs of daily life, and with the development of memory it is called a strong memory, and in contrast to its lack of development it becomes a weak memory. The success of an individual in business and other professions depends mainly on possessing a good memory that shows its value in following up the daily life which depends greatly on the degree of memory in which he maintains the shapes of faces, names, facts, events, circumstances, etc., from daily work-related matters and is a measure of his ability to accomplish tasks, which makes him a desirable member of society.

The role of memory is not only limited to activating the role of the individual in society, but rather it has a role in developing the individual himself through gathering the sections of the acquired knowledge and passing it on to the review stage before storing it, and this is done through the process of remembering the activity of memory).

Kay identified memory in her book entitled "Memory" that memory is the ability to develop

*Corresponding author: finea-dean@alexu.edu.eg 
without there being any form of doubt, as good memory is a means of preserving the mind by setting goals related to the future based on feelings and intellectual relationships between the eye and the ear.

Since memory is responsible for remembering past events and experiences and desperately needs them as a basic requirement of learning and self-protection, without it, we cannot face our present or plan our future based on future experiences, as Memory is the application of learning over time.

\section{Research Problem}

Are the illustrations highly capable and effective in treating short-term memory in children with special abilities?

\section{Research Objectives}

The research aims to recognize the effectiveness of the illustrations in treating short-term memory in children with special abilities.

\section{Research Limitations}

This research has spatial limits represented in an experimental study of children with special abilities within the Sondos Foundation for Orphans with Disabilities and Resala Charitable Foundation, and the temporal limits represented by the pre-school age group for children with special needs.

\section{Research Significance}

The importance of the research lies in finding unconventional methods using illustrations to treat short-term memory.

\section{Results}

Illustrations are important in treating short-term memory, which is the link between sensory memory and long-term memory.

The use of three-dimensional illustrations that attract the attention of children with special abilities in order to treat memory.

Using the sound and movement factor helps focus information in the short-term memory in preparation for its transfer to the long-term memory.

Repeating the graphic display more than once in an interactive way that helps treat short-term memory.

\section{Recommendations}

Illustrations should be used in the treatment of short-term memory for children with special abilities in educational institutions.

The movement, sound and repetition component of the three-dimensional drawings 
should be used to treat the short-term memory of children with special abilities within their educational institutions.

\section{References}

1. Annabel Thorn and Mike Page Interactions between Short Term and Long-Term Memory in the Verbal Domain - London and New York - Routledge, 2009.

2. BEATRICE MENSE, SUE DEBNEY AND TANYA DRUCE - Ready Set

3. Remember Short-Term Auditory Memory Activities - Australian Council for Educational Research - ACER Press, 2006.

4. Milton J. Dehn - Working Memory and Academic Learning Assessment and Intervention -canada - John Wiley \& Sons press, 2008.

5. Wolfgang Schneider University of Würzburg - Young Children's Cognitive Development Interrelationships Among Executive Functioning, Working Memory, Verbal Ability, and Theory of Mind - United States of America - Lawrence Erlbaum Associates, 2005.

6. Integra Staff - A Handbook on Learning Disabilities - Ontario - 2009.

7. William Walker Atkinson - Memory how to develop Train and use it - YOGeBooks by Roger 1 Cole, 2010.

8. Linda Chapel Jackson: Best practices in Classroom Management - Michigan State University - United Stated of America, 2004.

9. Professor Susan E. Gathercole \& Dr. Tracy Packiam Alloway - understanding working memory - S.E. Gathercole and T.P. Alloway, 2007.

10. Harold W. Percival: Man and Woman and Child - USA -the word foundation 1951

11. Dominic o Brien: How to develop a Perfect Memory? - Cambridge - Dominic O Brien, 1993.

12. - https://www.youtube.com/edit?o=U\&video_id=Fly2cAZSh6U

13. Wissam Hassan HASHEM, THE DESIGN PERFORMANCE OF INTERNAL SPACES AND ITS RELATIONSHIP TO THE SOCIAL VARIABLE: BAGHDAD CAFES ARE A MODEL, International Journal of Humanities and Language Research, Vol. 2, No. 2, 2019, pp. 9-19.

Received: March 2, 2020

Accepted: May 27, 2020 